\title{
Retraction Note to: Nafamostat mesilate inhibits the expression of HMGB1 in lipopolysaccharide-induced acute lung injury
}

\author{
Satoshi Hagiwara · Hideo Iwasaka · Takayuki Noguchi
}

Published online: 5 May 2015

(C) Japanese Society of Anesthesiologists 2015

Retraction Note to: J Anesth (2007) 21:164-170

DOI 10.1007/s00540-006-0468-8

This article published in J Anesth 2007;21:164-170 has been retracted by the Editor-in-Chief as Fig. 1C has been used to depict different experimental conditions in Fig. 1B in Eur J Pharmacol 2007;564:174-180. A decision of misconduct was reached after an investigation by Oita University.

The online version of the original article can be found under doi:10.1007/s00540-006-0468-8.

S. Hagiwara $(\bowtie) \cdot$ H. Iwasaka $\cdot$ T. Noguchi

Department of Brain and Nerve Science, Anesthesiology, Oita

University Faculty of Medicine, 1-1 Idaigaoka, Hasama-machi,

Yufu, Oita 879-5593, Japan 